\title{
Working
}

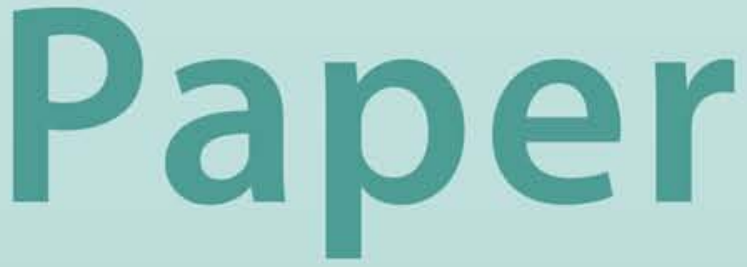


The Impact of the EMU on the Structure of European Equity Returns:

An Empirical Analysis of the First 21 Months

Thomas Kraus 


\title{
IMF Working Paper
}

\author{
Research Department
}

\section{The Impact of the EMU on the Structure of European Equity Returns: An Empirical Analysis of the First 21 Months}

\author{
Prepared by Thomas Kraus ${ }^{1}$ \\ Authorized for distribution by Donald Mathieson
}

June 2001

\begin{abstract}
The views expressed in this Working Paper are those of the author(s) and do not necessarily represcnt those of the IMF or IMF policy. Working Papers describe research in progress by the author(s) and are published to elicit comments and to further debate.
\end{abstract}

Using symmetric data sets of 92 weekly return observations before and after the introduction of the euro, the paper analyzes the impact of the new currency on the return structure of equity markets in the European Monetary Union. Variance decompositions, cluster analyses, and principle component analyses are used to explore the changes in the structural relations. European industry factors are found to have dramatically increased in importance with the launch of the single currency, and a new 'country-size' factor in European stock returns is detected. Furthermore, inner-European correlations are documented to have been reduced sharply with the start of the monetary union.

JEL Classification Numbers:F33, F36, G14, G15

Keywords: Euro, EMU, equity markets, correlations, industry sectors, factor models

Author's E-Mail Address: $\underline{\text { homas@kraus.ch }}$

\footnotetext{
${ }^{1}$ This paper was written while I was a Visiting Scholar to the IMF in Washington, D.C. I would like to thank Donald Mathieson for inviting me to the IMF's Research Department as well as for interesting discussions. Furthermore, I would like to thank Carl Andreas Claussen, Katrin Vernau and Matthias Vocke for valuable discussions and comments and Helen Hwang for formatting of the paper. All remaining errors remain-as usual-my own responsibility.
} 
I. Introduction

II. Data $\underline{5}$

III. Variance Decomposition of Stock Returns ..................................................... $\underline{6}$

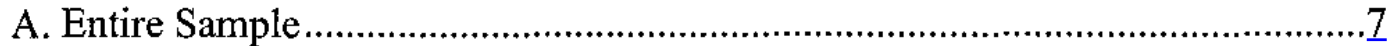

B. Grouping According to Countries .........................................................

C. Groupings According to Sectors ...........................................................

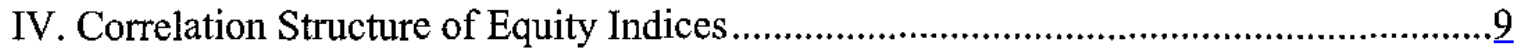

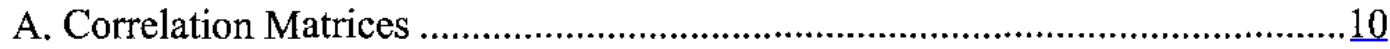

B. Cluster Analysis ................................................................................

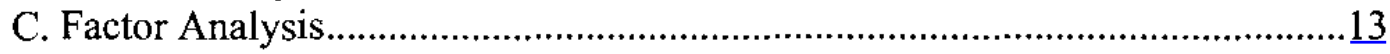

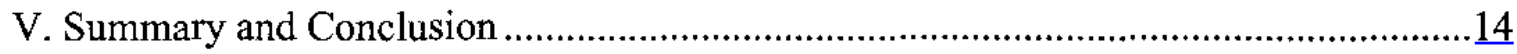

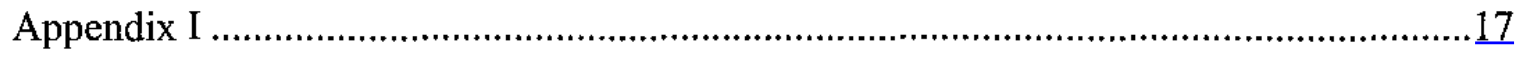

Text Tables

1. Number of Stocks, Grouped by Countries and Industry Groups ...............................19

2. Return Components Attributed to Each Factor Before and After

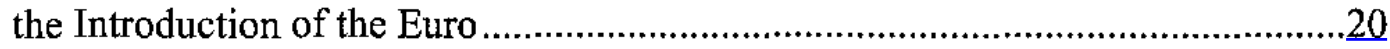

3. Variance Decomposition of Stocks Within European Countries Before and After the Introduction of the Euro ..........................................................................

4. Variance Decomposition of Stocks Within European Sectors Before and After the Introduction of the Euro ................................................................... 22

5. Country Correlations Before and After the Launch of the Euro .................................23

6. Sector Correlations Before and After the Launch of the Euro...................................24

7. Loadings of Rotated Country Factors Before the Launch of the Euro (04:97-12:98) ..25

8. Loadings of Rotated Country Factors After the Launch of the Euro (01:99-10:00) ....26

9. Loadings of Rotated Sector Factors Before the Launch of the Euro (04:97-12:98) .....27

10. Loadings of Rotated Country Factors After the Launch of the Euro (01:99-10:00)...28

Figures

1. Relative Market Capitalization of Stock Markets in the EMU ...................................29

2. Relative Market capitalization of Industry Sectors in the EMU ..................................

3. Variance Decomposition of the Entire Sample Before and After

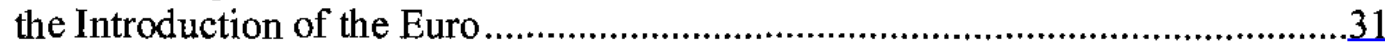

4. Variance Decomposition of Stocks According to Country Grouping After the Introduction of the Euro 
5. Differences in Variance Components of Single Stocks Before and After the Introduction of the Euro Grouped by Countries

6. Variance Decomposition of Stocks According to Country Grouping After the Introduction of the Euro

7. Differences in Variance Components of Single Stocks Before and After the Introduction of the Euro Grouped by Sectors .............................................

8. Dendogram of Country Indices Before (left) and After the Launch of the Euro (right)

9. Dendogram of Sector Indices Before (left) and After the Launch of the Euro (right) ..37

References. 


\section{INTRODUCTION}

On January 1, 1999, the European Monetary Union (EMU) became reality. Based on the Maastricht treaty, signed in December 1991, the Euro as the single European currency replaced the national currencies of the eleven participating countries, thus setting an end to the autonomy of national monetary policies in these countries. From here it is only a small step to the final phase in 2002 when the introduction of notes and coins will take place.

In addition to being one of the largest areas of economic activity, the Euro zone is also one of the most important capital markets in the world. The stock market capitalization in the currency area amounted to 5,526 bn. U.S. dollars as per end 1999, which makes it the second largest after the United States $\left(16,773 \mathrm{bn}\right.$.), but ahead of Japan $(4,455 \mathrm{bn}.){ }^{2}$ It is the aim of this paper to investigate empirically the effects of the start of the EMU on the return structure of European equities. Although there has already been a inner-European currency regime in place before the EMU (the European Monetary System, EMS), the launch of the Euro is of a new quality. Contrary to EMS, under EMU-regime the participating countries ultimately give up their monetary autonomy as well as any option for a revaluation of their currencies (such as in the EMS crisis in 1992-93). It is to be assumed that this fundamental change will have its effect on the behavior of market participants in the European equity markets.

Before the start of the EMU, several authors have been speculating about the potential effects of the Euro on European equity markets. ROUWENHORST (1999) sees no evidence for country specific factors to be of reduced importance in the EMU, rather, they will keep on dominating industry sector risks. BIAIS (1999) gets to the same conclusion by arguing that investors' home bias is not primarily caused by currency risk but rather by regulatory aspects and comparative advantages in the respective markets. Hence, country specific aspects will not be reduced in importance with the start of EMU - at least not in the short run. Studies by GOLDMAN SACHS INVESTMENT RESEARCH (1998) and by MORGAN STANLEY DEAN WITTER (1998) on the other hand predicted a fading out of country factors in favor of industry sector components, due to a reduced importance of country risks. BECKERS (1999) sees stocks within the same sectors to behave more and more alike, but the sectors themselves to lead increasingly independent lives. Looking at currency risks, he sees the EMU merely as a nonevent for international investors. DE SANTIS/GERARD/HILION (1999) focus on currency risk and its reward in the equity markets. They find the systematic risk caused by former EMS currencies to be small relative to the non-diversifiable risk caused by fluctuations of the U.S. dollar. Hence, the elimination of inner-European currency risk will have limited impact on international asset prices, risk and expected returns. The authors furthermore emphasize the benefits of enhanced liquidity, lower transaction costs and improved transparency in cross-country investments that come with the single currency. PRATI/SCHINASI (1997)

${ }^{2}$ Source: Bank for International Settlements (BIS) (2000) 
discuss the importance of an increased competition in an integrated European capital market. As a consequence, they see an increasing pressure for concentration among exchanges towards pan-European electronic trading platforms. Thereby, the EMU is likely to intensify cross-border trading and increase over-all market liquidity.

After the first 21 months, we have just enough data to investigate empirically what has really happened to European stock markets with the launch of the single currency. It is the aim of this study to empirically explore the changes in the return structure of European equities that came with the launch of the EMU. We are not about to test a set of restrictive hypotheses about the behavior of European stock markets, but rather attempt to describe any new patterns that can be observed on European equity markets. We will analyze how these structures changed with the introduction of the Euro and how this can be explained based on economic reasoning.

The article is structured as follows: Section II gives a brief description of the database used for the analyses. In Section III we are decomposing the variances of European stocks into their constituents and investigate the changes that came with the Euro. Section IV analyses in various forms the changes of the correlation structure of country and sector indices in the EMU. A critical review of the major insight in Section V concludes the article.

\section{DATA}

Our study builds on data from April 1997 to October 2000. Given the final data point, the period is chosen such that we get a symmetric data set of 92 weekly return observations around the event day. The event day is the formal start of the European Monetary Union on January $1,1999 .{ }^{3}$ We include country indices from ten of the eleven countries that are participating in the EMU, Luxembourg being the eleventh. We excluded Luxembourg because there is no stock from this country in the Dow Jones Euro STOXX ${ }^{\circledR}$ index which we will be using to select our sample of single stocks later in this paper. National stock markets are included on the basis of value-weighted Datastream total return indices. For the sector categorization, we build on the Dow Jones Euro STOXX ${ }^{\circledR}$ indices; an index family that has become very popular in the past years with asset managers all over Europe. The STOXX ${ }^{\circledR}$ sector classification distinguishes 18 European industry groups. ${ }^{4}$ The sector indices are weighted according to market values. We are using total return indices as provided by

${ }^{3}$ One could argue that it was not the actual launch of the Euro that opened the new era but rather the irrevocable fixing of the inner-European exchange rates. But since the two dates are very close together, the discussion is merely an academic one.

4 Throughout this article, we use the words 'sector', 'industry', 'industry sectors', and 'industry groups' as synonyms. 
STOXX $^{\circledR}$. Figure 1 and Figure 2 show the relative market values of the European countries and industry sectors under consideration; the graphs display average values for the time after the launch of the Euro.

Single stocks are integrated in our sample based on their inclusion in the DJ EURO STOXX $^{\circledR}$ index, the broad stock market index for the eleven EMU countries. As per October 2000 , there were 304 stocks included in this index. From these we eliminated 67 stocks that did not exist as such during the entire observation period. Leaving us with 237 stocks that are included on a total return basis. Table 1 gives an overview of the affiliation of these stocks to countries and sectors.

Throughout the study, we are using the U.S. dollar as the currency of reference. We deliberately do not use one of the European currencies as our numeraire. This would cause a bias in our results that we want to avoid. We know from earlier studies, e. g. ROLL (1992), HESTON/ROUWENHORST (1994), and HESTON/ROUWENHORST/WESSELS (1995), that the choice of the reference currency does not make a substantial difference for the type of questions we are about to address. As to what concerns the Euro as a new currency, we have to be very careful with the actual currency conversion. For the purpose of this study, we have converted all national currencies at the historic rates against the U.S. dollar, not via the irrevocable exchange rates against the Euro as they were fixed by the European heads of state in December 1998.

\section{VARIANCE DECOMPOSITION OF STOCK RETURNS}

In a first step, we are decomposing the variances of the 237 single stocks in our sample. For the periods before and after the introduction of the new currency, we do that by attributing them to different common sources of risk on one side and to an idiosyncratic component on the other. We are attributing a stock's return variance to four systematic sources of risk: A common World market and a European equity market factor as well as an individual country and a European sector factor.

In order to explore the return components of stock returns, we are estimating a sequence of factor models. The factors are added to our model, one after the other, in the following order: world, Europe, country, sector. We attribute the marginal $\mathrm{R}^{2}$ of each regression to the factor most recently added. ${ }^{5}$ We are aware of the fact that the sequence of factors crucially influences our results. Since our hypothesis to be falsified is a persistence of the return structure as it prevailed before the EMU, we are working with a factor sequence in accordance with the findings of earlier studies. We estimate the factor models separately for the period before the launch of the Euro and afterwards. The comparison of the results will

\footnotetext{
${ }^{5}$ The procedure is documented in the Appendix.
} 
allow us to see whether there has been a significant change in the importance of the risk factors under investigation.

Without focusing on a specific regime switch (such as the introduction of the Euro), similar techniques have been applied by DRUMMEN/ZIMMERMANN (1992), BECKERS/GRINOLD/RUDD/STEFEK (1992), HESTON/ROUWENHORST (1994), BECKERS/CONNOR/CURDS (1996), ROUWENHORST (1999), CAVAGLIA/BRIGHTMAN/AKED (2000), BACA/GARBE/WEISS (2000) and others. All of them, with the exception of CAVAGLIA/BRIGHTMAN/AKED, find country factors to heavily dominate industry factors in terms of their explanatory power. This is usually explained by the significance of country specific characteristics and events (fiscal policy, real and monetary shocks, etc.), by the well documented home bias of investors, and/or by the very specific sector profile of most countries. It will be of great interest to see whether this dominance of the country factor persists in an integrated European Monetary Union.

\section{A. Entire Sample}

Table 2 gives the results of the return decomposition for all stocks in the sample, Figure 3 visualizes the same data. Before the introduction of the Euro, we find the results to be consistent with those from earlier studies. The world factor is on average the most important return component (explaining 20.5 percent of total variance) followed by the individual country factor ( 9.3 percent). The European factor as well as the industry factor are less important. With the start of the EMU, however, things change dramatically. We find the world factor to sharply decrease in importance (- 11.9 percent of explanatory power) and the industry factor to significantly increase its explanatory power ( +6.0 percent), becoming the single most important component. This is the more remarkable as the industry factor is still last in the sequence of factors added to the model, thus only able to explain what is left over from the other factors. A re-grouping according to explanatory power would even more highlight the industry sector's increased importance. The country factor is slightly - but still significantly - reduced ( -2.2 percent) whereas the Europe-factor stays almost constant ( +0.3 percent). The average idiosyncratic component has increased from 57.9 percent to 65.7 percent of total risk with the introduction of the Euro. This means that the relative importance of diversifiable (non-systematic) risk of European equities has increased on average significantly with the new currency.

We interpret the reduced importance of the world market factor as an increased autonomy of the European equity market. With the start of the EMU, the European stock market seems to have become substantially more self-determined and less driven by other global markets. Maybe against our intuition, the reduced world factor is not substituted for by a European factor that has increased in importance. Rather, it is the specific industry factor that has gained explanatory power. The absolute and especially the relative importance of the industry factor has increased dramatically, making European equities primarily a sector issue 
after the launch of the new currency. This change is statistically significant at all conventional levels.

This is an important change with wide-ranging consequences. In contrast to all earlier studies for European equity markets we are for the first time able to empirically document a dominance of the industry factor over the country and even over the world market factor. ${ }^{6}$ We attribute this fundamental change clearly to the start of the EMU as an integrated economic zone with a single currency. We see two fundamental reason for the increased importance of European industry sectors: (1) With the abolition of the ten national monetary regimes, the importance of country specific factors has been reduced, although they clearly have not vanished. As a consequence, the risk exposures of a stock in a specific economic sector has become a lot more clearly attributable to its pan-European industry group. (2) With the start of the EMU, a substantial part of asset allocation strategies and of efforts in financial analysis has changed its focus from a country perspective to a European industry sector view. The new allocation of resources around the launch of the Euro may - in addition to the reasoning discussed before - have led to a self-fulfilling prophecy, thereby strengthening the sector profile of European equities. It is to be assumed that this is a selfenforcing process that will continue for the near future.

\section{B. Grouping According to Countrie}

Table 3 gives the return decomposition for stocks grouped according to countries. Figure 4 and Figure 5 display graphic visualizations. We find a dramatic reduction in the explanatory power of our four-factor model for the small stock markets of Austria (12.7 percent of explanatory power), Ireland (- 17.5 percent), and Portugal (- 18.6 percent) ${ }^{7}$ These reductions are primarily attributed to a diminished variance component of the world market factor, which is smallest for these three countries after the launch of the Euro (only 3.0 percent, 3.5 percent, and 7.0 percent respectively). The dramatic change in combination with the negligible importance of the world stock market factor after the Euro is specific to small countries, we do not observe it for large stock markets. We presume the existence of a 'small-country' factor that makes these markets react in a very particular way to the start of EMU. We collect more evidence on the existence of such a factor and discuss its nature in a later section of this article.

\footnotetext{
${ }^{6}$ Cavaglia/Brightman/Aked (2000) and Baca/Garbe/Weiss (2000) already document a growing importance of global sectors for international stock markets (world wide); they see them to be now roughly equal in importance to country factors.

${ }^{7}$ The average market capitalization shares of these markets are 0.7 percent, 1.5 percent, and 1.5 percent as can be seen from Figure 1 .
} 
The stocks in large countries, such as France, Germany, and the Netherlands are explained substantially above average by industry factors ( 7.0 percent, 9.4 percent and 7.7 percent before and 14.8 percent, 13.4 percent, and 16.3 percent after the launch of the Euro, respectively). This pattern can be found before and after the introduction of the Euro and, hence, does not seem to be caused by the launch of the new currency.

\section{Groupings According to Sectors}

Finally, we are decomposing stock return variance according to industry sector groups. Figure 6 gives the corresponding information for the EMU-phase and Figure 7 visualizes the changes associated with the conversion. The explicit numbers can be found in

Table 4. Before the EMU, we find the total of explained variance to range from 54.8 percent for the Auto industry to 29.7 percent for the Media sector; afterwards, these go from 58.6 percent for the Telecom sector to 16.0 percent for Industrial Goods \& Services.

In the pre-Euro period, the world factor was especially strong in explaining returns of the Auto industry (33.34 percent), the Basic Resources sector (27.37 percent), and the Chemical industry (26.81 percent). Interestingly enough, it is this group of sectors that has become extremely industry-driven with the introduction of the Euro. European sector factors explain on average as much as 19.0 percent, 44.84 percent and 32.82 percent of total variance for the three sectors, respectively. ${ }^{8}$ Although not as pronounced as the three industries just mentioned, the Energy sector proofs also to have been shifted from being strongly driven by the world market factor to being exceptionally exposed to the specific industry factor. These four 'resources oriented' sectors seem to react in a very particular way to the launch of the single currency in Europe. It seems that the arguments used before in favor of a more pronounced sector structure in Europe apply especially to these four sectors, presumably due to their large exposure towards price fluctuations of natural resources.

\section{CORRelation STRUCTURE OF EQUITY INDICES}

In this section, we are analyzing the correlation structure of European equity indices using different methodical approaches. We start with a direct comparison of the correlation matrices before and after the launch of the Euro. Next, we are running cluster analyses of equity indices to compare their grouping before and after the conversion. Finally, we are identifying independent common factors of European equity returns using a factor analysis.

\footnotetext{
${ }^{8}$ In the EMU-phase, the Energy and the Food \& Beverage sector show a slightly higher sector exposure than the Auto industry.
} 
A vast literature has investigated the evolution of international stock market correlations. Many authors find increases in stock market correlations to be strongly (positively) event-driven (such as the Gulf war, stock market crashes, emerging market crises, etc.). Among them are KING/WADHWANI (1990) and BERTERO/MAYER (1990). Others document a significant long-run increase in the correlations of national stock markets over the past years, e.g. FREIMAN (1998) and BECKERS (1999). KAPLANIS (1988) and RATNER (1992) on the other hand find no evidence for a significant change of correlation matrices in adjacent periods, however, LONGIN/SOLNIK (1995) reject the hypothesis of a constant correlation structure using conditional correlations.

\section{A. Correlation Matrices}

Table 5 gives the coefficients of correlations for all pairs of national stock markets in the EMU before and after the introduction of the Euro (lower left and upper right triangle, respectively). For visual clearness, all correlations above 0.5 are shaded. Just by looking at these shadings, we find correlations to have been lowered remarkably with the launch of the Euro. Almost all country combinations showed a significant reduction of correlations with the launch of the Euro. ${ }^{9}$ The average correlation between national markets went down from 0.63 before the conversion to 0.49 afterwards. Assuming a normal distribution of average correlations, this change is significant at the 1 percent-level. Notable exceptions to this general reductions are the significantly increased correlations (dark shading) of Italy with other markets, in particular with the German and the French stock markets. We understand that the disappearance of the Lira as a autonomous currency made the Italian stock market move towards the European core markets.

Following JENNRICH (1970), we test for the equality of the correlation matrices as a whole before and after the currency conversion. ${ }^{10}$ The resulting test statistic of 90.0 is chisquared distributed and with 45 degrees of freedom significant at all plausible levels.

We find the same general pattern of correlation changes in an even more pronounced manner when looking at the links between European industry sectors. Table 6 gives the corresponding information. Whereas almost all correlations between industry sectors were above 0.5 before the introduction of the Euro (shadings in lower left triangular), the majority was clearly below that level after the conversion (upper right triangular). The average correlation between industry sectors went down from 0.64 to 0.38 , which is a substantially

\footnotetext{
${ }^{9}$ The Fisher transformation for the test of equality of correlation coefficients is documented in the appendix.

${ }^{10}$ The Jennrich (1970) test is documented in the appendix.
} 
more pronounced reduction than for country correlations $(0.63$ to 0.49$)$. Again, the reduction is significant at the 1 percent-level. Based on the JENNRICH (1970) test, we also reject the hypothesis of an equality of the two succeeding correlation matrices with a test statistic of 266.5 with 153 degrees of freedom at all standard levels of confidence.

Of all the 18 industries, we find only the Media sector's correlation with the Technology and the Telecom sector to have increased significantly (from 0.54 to 0.73 and from 0.58 to 0.75 ). This approaching within the TMT sector (Telecom, Media, Technology) was presumably caused primarily by the global tech rally on international stock markets of the late 1990s; it may, however, very well have been bolstered at the same time by an accelerated Europeanizing of this industry due to the single currency.

Overall, the results of these correlation analyses are only partly consistent with our first economic intuition. The introduction of the single currency was the ultimate end of national monetary policies, of differing interest rate and exchange rate regimes in the monetary union. We would therefore expect country specific factors to have become of negligible importance in the EMU. Instead, European industry sectors should have become more disperse due to more pronounced factor profiles that are not blurred by country factors anymore. In sum, we would find an increase of country correlations and a decrease of sector correlations to go along with the introduction of the single currency.

What we find in our data, however, only partly confirms our expectations. In accordance with our hypothesis, we do find lowered correlations between European industry sectors. At the same time, we observe correlations between country indices to have gone down as well. Why did this happen? We have a very simple explanation for this finding that goes back to RoLL (1992): '...we can conclude that a significant portion of the international pattern of correlations is due to the industrial structures of countries.' Going back to Table 1 we find indeed a very uneven allocation of European industry sectors across the ten national stock markets: eight out of the ten car producers in our sample are in France and in Germany, 14 of the 33 banks are Italian (Italy has all in all 44 stocks in the sample), five of the fourteen utility suppliers are in Spain (Spain having a total of 19 stocks under investigation), the retail sector with its ten stocks is present in only three of the ten countries, etc.

Knowing about the asymmetrical industrial structure of the European countries, we are not too surprised to find a reduction of correlations for sectors as well as for countries, whereby the average correlation in the former case is reduced more than in the latter $(-0.26$ vs. - 0.14). This is not to say that the launch of the Euro did not reduce the importance of the country factor (see also the results of variance decomposition in the previous section). Rather, the removal of (some) country specific factors made the European industry sectors more disperse, thus lowering country correlations at the same time. 


\section{B. Cluster Analysis}

In order to get yet another notion of the correlation structure of equity market returns, we conduct cluster analyses for the time periods before and after the introduction of the Euro. We are running a hierarchical clustering procedure based on correlation coefficients between the indices. We use complete linkages such that the most distant pair of indices in two clusters is used to calculate the between-cluster distance. That way, we produce compact clusters of country or sector indices.

Figure 8 gives the dendograms for country indices before and after the launch of the Euro. The distance measure used is $(1-\rho)$, i. e. if two indices are joined at, e. g., 0.3 they are correlated at 0.7 . The most remarkable difference between the two diagrams is the very clear formation of a cluster of large countries after the launch of the Euro. We find the five national stock markets with the highest market capitalizations to form a very sharp cluster of their own, which is clearly separated from the other five markets. ${ }^{11}$. These large markets are Germany (on average 25.5 percent of total EMU market capitalization), France (25.1 percent), the Netherlands ( 15.0 percent), Italy (14.1 percent), and Spain (7.5 percent). What is particularly interesting, is that it was only with the introduction of the Euro that Italy and Spain joined this group of European core markets. This confirms our earlier findings. As was mentioned before, we presume the existence of factors specific to these countries (e. g. their individual monetary policy) that kept investors from perceiving them - despite their substantial market capitalizations - as being part of the group of major European markets.

The results of the analyses for European industry sectors as displayed in Figure 9 give us interesting insights into the prevailing sector grouping. When comparing the two diagrams, we find the clustering of European sectors after the launch of the new currency to be economically much more meaningful than before. In the EMU-period we are able to identify economic 'super sectors' such as 'TMT' (consisting of 'Telecom', 'Media', and 'Technology'), 'Financial' ('Banks', 'Insurance', and 'Financial Services'), 'Subsistence' ('Healthcare' and 'Food and Beverage'), and 'Basic industries' ('Basic resources', 'Energy', 'Chemical', and 'Auto'). Such economically meaningful groupings of industries did not exist before the start of the EMU. ${ }^{12}$ Rather, the clustering of the industry sectors was somewhat erratic. Furthermore, we find that with the introduction of the Euro, the identified clusters have become remarkably more disperse. ${ }^{13}$ We even find the top level clusters to be

${ }^{11}$ Market capitalization did not influence the formation of these clusters since every national stock market is equally treated in the analysis.

12 Undoubtedly, the formation of these 'super sectors' heavily depends on the chosen industry classification.

${ }^{13}$ This is not necessarily the same result that emerged in the previous sub-section. A lower average correlation of sectors does not necessarily imply that clusters of industry sectors (or clusters of clusters) are consistently correlated at a lower level than before. 
negatively correlated to each other, and the second level groupings still to have almost zerocorrelations.

All this supports our previous findings that the introduction of the Euro made the individual risk profiles of industry sectors more important, more pronounced, and more diverse. Industry risks are less overshadowed by country specific factors. Hence, with a single currency, similar economic segments are grouping in some kind of 'super sectors', whereas dissimilar segments are more clearly separated by capital market participants than they were before.

\section{Factor Analysis}

Running a factor analysis, we are further exploring the multivariate return structure of European equities before and after the introduction of the Euro. A factor analysis identifies a limited number of orthogonal factors that govern the correlation structure of asset returns. ${ }^{14}$ These factors are a-priori unknown and are constructed as linear combinations of existing time series. We are using principal component analysis to extract the factors. The number of independent components we are identifying is set by the Kaiser criterion which demands the factors' eigenvalues to be greater than 1.0. ${ }^{15}$ The identified factors are then rotated by the varimax-method. DRUMMEN/ZIMMERMANN (1992), HESTON/ROUWENHORST/WESSELS (1995), NAUGHTON (1996), and others also use this technique of a multivariate factor analysis to explore the structure of international stock market returns.

Table 7 and Table 8 give the loadings of the rotated country factors before and after the launch of the Euro. These loadings are the coefficients of correlation between the respective country index and the unknown factors. The tables are sorted by loadings in order to give a better overview of the driving components. We identify two factors fulfilling the Kaiser criterion. Together they explain 75.9 percent and 70.3 percent of total variance before and after the Euro introduction, respectively.

It is very straight forward to interpret the common factors in the EMU-period as a 'large-country' factor and a 'small-country' factor. The matching of countries to the two factors is perfectly consistent with the rankings of their market capitalizations (Figure 1), with the only exception of Portugal, which happens to be higher correlated with the largecountry factor $(0.68)$ than with the small-country factor $(0.15)$, although its market

\footnotetext{
${ }^{14}$ The analysis could also build on the covariance structure instead of the correlation structure. This, however, would lead to a stronger weighting of high-volatility input series.

${ }^{15}$ Since we are always looking at two sub-periods, we demand the eigenvalues to be greater than 1.0 in at least one of the two sub-periods.
} 
capitalization is the third smallest. In the pre-Euro phase, the grouping of stock markets did not yield such a clear pattern.

In two earlier sections we have already collected evidence for the existence of a country-size factor that has affected stock returns in the EMU in a fairly particular way (when decomposing the variances of stock returns, we found small countries to react in a very special way to the launch of the Euro; the cluster analysis of stock market returns showed a strikingly clear clustering of large markets after the start of the EMU). The results of the factor analysis just conducted provide further evidence for the existence of such a country-size factor that has become especially important with the launch of the single currency in Europe. We are not able to give a consistent economic explanation for the existence of this country-size factor. However, we know it does exists in the EMU countries and it became especially pronounced with the introduction of the single currency. It does not seem to be caused by a different industrial structure of large and small countries nor by contrasting exposures towards global risk factors. ${ }^{16}$ HESTON/ROUWENHORST (1994) and HESTON/ROUWENHORST/WESSELS (1995) also identify a large country factor in their data sample. They discuss how the presence of such a large country factor makes it very difficult to replicate the factor portfolios of small countries (e.g. Austria) using factor portfolios of large countries (e. g. Germany). They attribute this to the presence of large country specific component of return variation but are also unable to give further economic intuition on the phenomenon.

When looking at the results of the factor analysis for European sector returns in Table 9 and Table 10, we find a remarkable reduction of the explanatory power of the three identified factors (76.8 percent vs. 68.8 percent of total variance). This is just another aspect of the earlier finding that correlations between European sectors were reduced substantially with the introduction of the Euro, leading to an increased relative importance of unsystematic vis-à-vis systematic risk. This has already been documented in an earlier section.

Whereas the first factor after the launch of the Euro is hard to interpret, we find the second and third factor to represent a TMT-factor and a 'Basic industries' factor, respectively. Again, this supports earlier findings.

\section{SUMMARY AND CONCLUSION}

After the first 21 months of experience with the Euro as the single currency in the EMU countries we are able to gather first evidence on its impact on the return structure of European equity markets. From a variety of different empirical analyses we were able to

\footnotetext{
${ }^{16}$ The country exposures towards global risk factors are not documented in this paper; they can be received from the author upon request.
} 
isolate three central insights about the impact of the new currency on European equity markets, as they have not been documented in the literature before.

- With the currency conversion, a 'country-size' factor emerges

We find repeated evidence for the existence of a 'country-size' factor that became especially pronounced after the introduction of the Euro. One very interesting aspect of this is that it was only with the start of the EMU that countries such as Italy or Spain joined the group of European core markets. Factors specific to these countries (e.g. their specific monetary and fiscal policy) seem to have kept equity market investors from perceiving them as major European stock markets before the start of the monetary union.

- Industry sectors have become the driving forces in the European equity markets Clearly contradicting all studies on earlier time periods, we find European industry sectors to have become the major driving force of stock returns in the European Monetary Union. Sector factors account for 12.0 percent of total return variance after the start of the EMU as compared to 6.0 percent before. Furthermore, since the start of the single currency, industry sectors are observed to have formed clusters of what we identified as 'super-sectors', such as 'TMT', 'Basic industries', 'Financial', and 'Subsistence'.

- Correlations between sectors and between countries have significantly been reduced With the end of the various national currency regimes, the risk profiles of pan-European industry sectors have become substantially more pronounced and therefore more diverse, leading to significantly reduced correlations. Against our first intuition, we also find the correlations between countries to have been reduced with the start of the EMU. We attribute this to the uneven allocation of industries across European countries - an aspect that is often neglected in the literature.

These insights have quite some practical implications. Where this has not already happened, financial analysis as well as asset allocation processes for continental Europe will have to get organized by industry groups or even by what we called 'super-sectors' rather than by countries. Undoubtedly this will further strengthen the dominance of sector over country factors. As the importance of country specific factors diminishes, so does the potential for national (fiscal) policy to have an impact on a country's stock market. Yet another aspect of our findings is the structural break per se that came with the new currency (changes in correlations, increases in idiosyncratic risks, importance of sector factors, etc.). Such a dramatic change should be accounted for in the management of market risks, in corporate finance decisions, as well as in all investment evaluations.

It is left to further research to explore the economic nature of the country-size factor we have detected so clearly since the start of the EMU. As soon as longer time series are available it will also be of great interest to learn whether the introduction of the Euro brought along a change in the compensation for bearing systematic risks in the European equity markets. 
For now, we see the Euro's first 21 month to have brought along more changes than we - and many authors with us - might have anticipated. Some of the changes in European equity returns were to be expected, others are quite surprising and will ask for additional research-attention if they persist. 


\section{Fisher r-to-z transformation}

To test two (independent) sample correlation coefficients for equality $\left(\rho_{1}=\rho_{2}\right)$, we have to transform each of them according to

$$
z_{.}=0.5 \times \ln \left(\frac{1+\rho .}{1-\rho .}\right)
$$

The test statistic

$$
\frac{z_{1}-z_{2}}{\sqrt{\frac{1}{n_{1}-3}+\frac{1}{n_{2}-3}}}
$$

is then standard normally distributed for sufficiently large numbers of observations $(n)$.

\section{JENNRICH test}

JENNRICH (1970) defined a test for the equality of two sample correlation matrices $\left(\mathrm{R}_{1}\right.$ $=\mathrm{R}_{2}$ ). The following test statistic is asymptotic $\chi^{2}$-distributed with $[1 / 2 \mathrm{p}(\mathrm{p}-1)]$ degrees of freedom, $\mathrm{p}$ standing for the dimension of the two matrices.

$$
\frac{1}{2} \operatorname{tr}\left(Z^{2}\right)-(\operatorname{dg}(Z)) S^{-1} \mathrm{dg}(Z)
$$

$\operatorname{tr}($.) defines the trace of a matrix and $\mathrm{dg}($.) constitutes the column vector consisting of the diagonal elements of a matrix. For an equal number of observations (n), which is the case for our application, the matrix $\mathrm{Z}$ is defined as

$$
Z=\sqrt{\frac{n}{2}}\left(\frac{1}{2}\left(R_{1}+R_{2}\right)\right)^{-1}\left(R_{1}-R_{2}\right)
$$

The matrix $\mathrm{S}$ is defined by its single elements as

$$
\mathrm{S}=\left(\frac{1}{2}\left(\mathrm{R}_{1}+\mathrm{R}_{2}\right)\right)_{\mathrm{ij}} \times\left(\frac{1}{2}\left(\mathrm{R}_{1}+\mathrm{R}_{2}\right)\right)^{-1} \mathrm{ij}+\delta_{\mathrm{ij}}
$$

whereby $\delta_{\mathrm{ij}}$ stands for the Kroneker delta. 


\section{Variance Decomposition}

The variance of a single stock (i) is decomposed by regressing its weekly returns (r) on the four factors world (w), Europe (e), country, and industry sector. The factors are added subsequently to the model, thereby assigning the incremental $\mathrm{R}^{2}$ as variance component caused by the latest factor added to the model. The procedure is as follows: We start by regressing the returns of stock $i$ on the returns of the world market:

$$
r_{i}=\alpha_{1}+\beta_{1} r_{w}+\widetilde{\varepsilon}_{i, 1}
$$

yielding a variance component of the world market factor of

$$
1-\frac{\sum_{i} \widetilde{\varepsilon}_{i, 1}}{\sum_{i} r_{i}}
$$

In a next step, the returns of stock $i$ are regressed on the world market and on the Europe factor simultaneously:

$$
r_{i}=\alpha_{2}+\beta_{2} r_{w}+\gamma_{2} r_{e}+\widetilde{\varepsilon}_{i, 2}
$$

To find the variance component explained by the Europe factor we calculate the marginal $\mathrm{R}^{2}$ as

$$
1-\frac{\sum_{i} \widetilde{\varepsilon}_{i, 2}}{\sum_{i} r_{i}}-\left(1-\frac{\sum_{i} \widetilde{\varepsilon}_{i, 1}}{\sum_{i} r_{i}}\right)=\frac{\sum_{i} \widetilde{\varepsilon}_{i, 1}-\sum_{i} \widetilde{\varepsilon}_{i, 2}}{\sum_{i} r_{i}}
$$

The procedure continues until every factor is included in the model. 
Table 1: Number of Stocks, Grouped by Countries and Industry Groups

\begin{tabular}{|c|c|c|c|c|c|c|c|c|c|c|c|}
\hline & Austria & Belgium & Finland & France & Germany & Ircland & Italy & Netherl. & Portugal & Spain & Sum \\
\hline Auto & & & & 4 & 4 & & 2 & & & & 10 \\
\hline Banks & 1 & 2 & & 2 & 5 & 2 & 14 & 1 & 2 & 4 & 33 \\
\hline Basic resources & & & 2 & 2 & 1 & 1 & & & & 1 & 7 \\
\hline Chemical & & 1 & & 1 & 3 & & & 2 & & & 7 \\
\hline Construction & & & & 6 & 1 & 1 & & & 1 & 3 & 12 \\
\hline Cycl. goods \& serv. & & & & 7 & 3 & & 4 & 1 & & & 15 \\
\hline Energy & 1 & & & 2 & & & 2 & 2 & & 2 & 9 \\
\hline Financial services & & 2 & & 4 & 3 & & 1 & 2 & 1 & 1 & 14 \\
\hline Food \& beverages & & & & 3 & & 1 & 2 & 5 & & & 11 \\
\hline Healthcare & & 1 & & 3 & 5 & 1 & & 1 & & & 11 \\
\hline Inds. goods \& serv. & & 1 & 1 & 8 & 4 & & 3 & 2 & & 1 & 20 \\
\hline Insurance & & & 1 & 3 & 4 & 1 & 6 & 1 & & & 16 \\
\hline Media & & & & 6 & & 1 & 3 & 3 & & & 13 \\
\hline Non-cycl. goods & & 2 & & 3 & 2 & & & 2 & 1 & 1 & 11 \\
\hline Retail & & & & 4 & 3 & & & 3 & & & 10 \\
\hline Technology & & & 2 & 7 & 2 & & 1 & 3 & & & 15 \\
\hline Telecom & & & & & 2 & & 3 & 1 & 2 & 1 & 9 \\
\hline Utility Suppliers & & 2 & & 2 & 2 & & 3 & & & 5 & 14 \\
\hline Sum & 2 & 11 & 6 & 67 & 44 & 8 & 44 & 29 & 7 & 19 & 237 \\
\hline
\end{tabular}


Table 2: Return Components Attributed to Each Factor Before and After the Introduction of the Euro Differences that are Significant at the 1 Percent-level are Marked with ***

\begin{tabular}{lrrrr}
\hline & $\begin{array}{r}\text { Before Euro } \\
\text { introduction }\end{array}$ & $\begin{array}{r}\text { After Euro } \\
\text { introduction }\end{array}$ & Difference \\
\cline { 2 - 5 } World & $20.5 \%$ & $8.6 \%$ & $-11.9 \%$ & $* * *$ \\
Europe & $6.4 \%$ & $6.7 \%$ & $+0.3 \%$ & \\
Country & $9.3 \%$ & $7.1 \%$ & $-2.2 \% \%^{* * *}$ \\
Sector & $6.0 \%$ & $12.0 \%$ & $+6.0 \% \%^{* * *}$ \\
Unexplained & $57.9 \%$ & $65.7 \%$ & $+7.8 \% \%^{* * *}$ \\
\hline
\end{tabular}


Table 3: Variance Decomposition of Stocks Within European Countries Before and After the Introduction of the Euro

\begin{tabular}{|c|c|c|c|c|c|c|c|c|c|c|c|}
\hline Before Euro & $\begin{array}{l}\text { Austria } \\
\text { introduction }\end{array}$ & Belgium & Finland & France & Germany & Ireland & Itely & Ireland & Portugal & Spain & Average \\
\hline Norld & $18.5 \%$ & $23.2 \%$ & $30.4 \%$ & $18.2 \%$ & $22.0 \%$ & $21.8 \%$ & $16.3 \%$ & $24.7 \%$ & $33.3 \%$ & $18.7 \%$ & $22.7 \%$ \\
\hline Eurape & $5.1 \%$ & $7.4 \%$ & $3.9 \%$ & $8.3 \%$ & $5.6 \%$ & $1.0 \%$ & $6.2 \%$ & $5.1 \%$ & $6.6 \%$ & $6.0 \%$ & $5.5 \%$ \\
\hline Country & $29.3 \%$ & $12.4 \%$ & $17.9 \%$ & $4.1 \%$ & $4.8 \%$ & $22.5 \%$ & $15.1 \%$ & $5.5 \%$ & $24.9 \%$ & $12.2 \%$ & $14.9 \%$ \\
\hline Sector & $1.8 \%$ & $2.8 \%$ & $5.1 \%$ & $7.0 \%$ & $9.4 \%$ & $1.8 \%$ & $3.6 \%$ & $7.7 \%$ & $1.4 \%$ & $4.0 \%$ & $4.5 \%$ \\
\hline Unexplained & $45.3 \%$ & $54.2 \%$ & $42.7 \%$ & $62.5 \%$ & $58.1 \%$ & $52.9 \%$ & $58.8 \%$ & $56.9 \%$ & $33.9 \%$ & $59.1 \%$ & $52.5 \%$ \\
\hline \multicolumn{12}{|c|}{ After Euro introduction } \\
\hline World & $3.0 \%$ & $7.7 \%$ & $12.3 \%$ & $8.8 \%$ & $8.6 \%$ & $3.5 \%$ & $9.6 \%$ & $7.9 \%$ & $7.0 \%$ & $9.0 \%$ & $7.7 \%$ \\
\hline Europe & $1.6 \%$ & $4.9 \%$ & $1.9 \%$ & $6.5 \%$ & $6.7 \%$ & $2.5 \%$ & $8.5 \%$ & $4.6 \%$ & $12.0 \%$ & $9.3 \%$ & $5.9 \%$ \\
\hline Country & $36.2 \%$ & $28.4 \%$ & $10.3 \%$ & $2.1 \%$ & $3.5 \%$ & $18.2 \%$ & $5.3 \%$ & $7.5 \%$ & $24.3 \%$ & $8.8 \%$ & $14.5 \%$ \\
\hline Sector & $1.2 \%$ & $4.1 \%$ & $22.3 \%$ & $14.8 \%$ & $13.4 \%$ & $5.3 \%$ & $8.8 \%$ & $16.3 \%$ & $4.2 \%$ & $7.9 \%$ & $9.8 \%$ \\
\hline Unexplained & $58.0 \%$ & $54.8 \%$ & $53.1 \%$ & $67.7 \%$ & $67.9 \%$ & $70.5 \%$ & $67.9 \%$ & $63.6 \%$ & $52.5 \%$ & $65.0 \%$ & $62.1^{\circ}$ \\
\hline \multicolumn{12}{|l|}{ Differences } \\
\hline World & $-15.5 \%$ & $-15.5 \%$ & $-18.1 \%$ & $-9.3 \%$ & $-13.5 \%$ & $-18.3 \%$ & $-6.7 \%$ & $-16.8 \%$ & $-26.3 \%$ & $-9.7 \%$ & $-15.0 \%$ \\
\hline Europe & $-3.5 \%$ & $-2.5 \%$ & $-1.9 \%$ & $-1.8 \%$ & $1.1 \%$ & $1.5 \%$ & $2.2 \%$ & $-0.5 \%$ & $5.4 \%$ & $3.4 \%$ & $0.3 \%$ \\
\hline Country & $7.0 \%$ & $16.0 \%$ & $-7.6 \%$ & $-2.0 \%$ & $-1.3 \%$ & $-4.3 \%$ & $-9.8 \%$ & $1.9 \%$ & $-0.5 \%$ & $-3.5 \%$ & $-0.4 \%$ \\
\hline Sector & $.0 .6 \%$ & $1.4 \%$ & $17.3 \%$ & $7.8 \%$ & $4.0 \%$ & $3.6 \%$ & $5.2 \%$ & $8.6 \%$ & $2.8 \%$ & $3.9 \%$ & $5.4 \%$ \\
\hline Unexplained & $12.7 \%$ & $0.6 \%$ & $10.4 \%$ & $5.2 \%$ & $9.7 \%$ & $17.5 \%$ & $9.1 \%$ & $6.7 \%$ & $18.6 \%$ & $5.9 \%$ & 9.7 \\
\hline
\end{tabular}


Table 4: Variance Decomposition of Stocks Within European Sectors Before and After the Introduction of the Euro

\begin{tabular}{|c|c|c|c|c|c|c|c|c|c|c|c|c|c|c|c|c|c|c|c|}
\hline \multicolumn{3}{|c|}{$\begin{array}{l}\text { Auto Banks } \\
\text { Before Euro introduction }\end{array}$} & \multicolumn{3}{|c|}{ Basic res. Chemical Constr. } & \multicolumn{2}{|c|}{ Cycl. G. Energy } & Financial & \multicolumn{2}{|c|}{ ood \& betlealthc. } & \multicolumn{3}{|c|}{ Inds. Goo Insurance Media } & \multicolumn{2}{|c|}{ Non-cyci. Retail } & Techn. & Felecom & Jtilities & Average \\
\hline Norld & $33.3 \%$ & $23.2 \%$ & $27.4 \%$ & $26.8 \%$ & $16.7 \%$ & $21.8 \%$ & $19.4 \%$ & $25.3 \%$ & $18.0 \%$ & $18.4 \%$ & $19.0 \%$ & $22.4 \%$ & $10.6 \%$ & $20.5 \%$ & $13.2 \%$ & $21.3 \%$ & $21.6 \%$ & $12.5 \%$ & $20.6 \%$ \\
\hline & $8.1 \%$ & $5.5 \%$ & $4.2 \%$ & $5.9 \%$ & $5.6 \%$ & $4.8 \%$ & $4.0 \%$ & $7.0 \%$ & $7.2 \%$ & $5.4 \%$ & $5.7 \%$ & $5.8 \%$ & $6.9 \%$ & $9.9 \%$ & $5.3 \%$ & 6.5\% & $7.8 \%$ & $9.7 \%$ & $6.4 \%$ \\
\hline & $5.7 \%$ & $15.4 \%$ & $8.8 \%$ & $7.6 \%$ & $6.0 \%$ & $4.7 \%$ & $11.4 \%$ & $8.2 \%$ & $10.2 \%$ & $6.5 \%$ & $4.0 \%$ & $16.3 \%$ & $4.3 \%$ & $8.7 \%$ & $5.1 \%$ & $6.4 \%$ & $18.7 \%$ & $11.8 \%$ & $8.9 \%$ \\
\hline & $7.6 \%$ & $5.7 \%$ & $9.2 \%$ & $7.9 \%$ & $6.1 \%$ & $3.9 \%$ & $11.5 \%$ & $4.3 \%$ & $3.6 \%$ & $6.1 \%$ & $2.7 \%$ & $5.8 \%$ & $7.9 \%$ & $3.4 \%$ & $7.6 \%$ & $9.4 \%$ & $4.0 \%$ & $7.6 \%$ & $6.3 \%$ \\
\hline & $45.2 \%$ & $50.2 \%$ & $50.4 \%$ & $51.8 \%$ & $65.6 \%$ & $64.8 \%$ & $53.8 \%$ & $55.2 \%$ & $61.0 \%$ & $63.6 \%$ & $68.6 \%$ & $49.8 \%$ & $70.3 \%$ & $57.6 \%$ & $68.8 \%$ & $56.4 \%$ & $48.0 \%$ & $58.4 \%$ & $57.8 \%$ \\
\hline \multicolumn{20}{|c|}{ fter Euro introduction } \\
\hline arld & $5.3 \%$ & $10.0 \%$ & $2.7 \%$ & $5.3 \%$ & $4.8 \%$ & $9.6 \%$ & $4.2 \%$ & $9.5 \%$ & $2.2 \%$ & $4.5 \%$ & $6.9 \%$ & $8.0 \%$ & $11.4 \%$ & $5.4 \%$ & $5.7 \%$ & $22.0 \%$ & $18.8 \%$ & $8.6 \%$ & $8.0 \%$ \\
\hline & $5.4 \%$ & $7.5 \%$ & $2.7 \%$ & $5.6 \%$ & $4.4 \%$ & $5.6 \%$ & $2.9 \%$ & $6.3 \%$ & $3.9 \%$ & $5.3 \%$ & $5.4 \%$ & $9.5 \%$ & $8.7 \%$ & $4.0 \%$ & $3.3 \%$ & $9.7 \%$ & $17.6 \%$ & $8.5 \%$ & $6.5 \%$ \\
\hline & $1.9 \%$ & $11.9 \%$ & & $10.7 \%$ & $4.9 \%$ & $2.1 \%$ & $9.0 \%$ & 11.9 & 5.5 & $5.9 \%$ & 2.2 & 9.2 & $2 s$ & 9.5 & 4.0 & 6.9 & 10.7 & $9.8 \%$ & $6.7 \%$ \\
\hline Unexplained & $68.5 \%$ & $62.1 \%$ & $48.1 \%$ & $45.6 \%$ & $76.4 \%$ & $76.7 \%$ & $61.9 \%$ & $60.5 \%$ & $68.1 \%$ & $79.3 \%$ & $84.0 \%$ & $63.8 \%$ & $59.3 \%$ & $72.8 \%$ & $73.5 \%$ & $52.4 \%$ & $41.4 \%$ & $65.2 \%$ & $64.4 \%$ \\
\hline \multirow{2}{*}{\multicolumn{20}{|c|}{ Differences }} \\
\hline & & & & & & & & & & & & & & & & & & & \\
\hline & $-2.8 \%$ & $2.0 \%$ & $-1.4 \%$ & $-0.3 \%$ & $-1.2 \%$ & $0.8 \%$ & $-1.1 \%$ & -0.7 & $-3.2 \%$ & -0.1 & -0.2 & & & -5.9 & -2.0 & 3.2 & 9.8 & $-1.2 \%$ & 0.1 \\
\hline & $-3.8 \%$ & $-3.5 \%$ & -7.1 & 3.1 & -1.1 & $-2.5 \%$ & $-2.4 \%$ & 3.7 & -4.7 & -0.6 & -1.8 & -7.1 & -1.4 & & $-1.1 \%$ & 0.5 & $-8.0 \%$ & $-2.0 \%$ & $-2.2 \%$ \\
\hline & $11.3 \%$ & $2.8 \%$ & $35.6 \%$ & $25.0 \%$ & $3.5 \%$ & $2.1 \%$ & $10.5 \%$ & $7.4 \%$ & $16.7 \%$ & $-1.1 \%$ & $-1.2 \%$ & $3.5 \%$ & & $5.0 \%$ & $5.9 \%$ & $-0.4 \%$ & $7.6 \%$ & $0.4 \%$ & $8.0 \%$ \\
\hline Inexplained & $23.3 \%$ & $11.8 \%$ & $-2.3 \%$ & $-6.2 \%$ & $10.8 \%$ & $11.8 \%$ & $8.1 \%$ & $5.4 \%$ & $7.0 \%$ & $15.7 \%$ & $15.4 \%$ & $14.4 \%$ & $-11.0 \%$ & $15.2 \%$ & $4.7 \%$ & $-4.0 \%$ & $-6.6 \%$ & $6.7 \%$ & $6.7 \%$ \\
\hline
\end{tabular}


Table 5: Country Correlations Before and After the Launch of the Euro

(lower left and upper right triangle, respectively)

Correlations of over 0.5 are shaded. $*, * *$, and $* * *(+,++$, and +++$)$ mark significant reductions (increases) at the 10 percent - , 5 percent- and 1 percent-level of significance, respectively

\begin{tabular}{|c|c|c|c|c|c|c|c|c|c|c|}
\hline & Austria & Balgium & Finland & France & Germaty & frcland & lataly & ticthetands & Portugal & Spain \\
\hline Austria & 60075 & $05 \%$ & $0.04^{* * *}$ & $0.32^{* * * *}$ & $0.41^{* * *}$ & 0.39 & $0.29^{* * * *}$ & w501 & $0.17^{* * * *}$ & $0.40^{* *}$ \\
\hline Belgium & 663 & 100 & $0.06^{* * * *}$ & $0.46 * * *$ & $0.47^{* * *}$ & 0.43 & $0.36^{* *}$ & 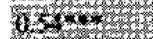 & $0.27^{* * *}$ & $0.48^{* * *}$ \\
\hline Finland & $0 \%$ & 0.58 & tow: & $0,61 \%$ & 65407 & $0.25^{* * *}$ & 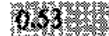 & $0.45^{* * *}$ & 0.40 & $0.40^{* *}$ \\
\hline France & hool: & 0.75 & 1063 & 100 & $0.82 \%$ & 0.37 & $6024+4$ & 673 & $0, y_{3}$ & 076 \\
\hline Gernany & $0,68:$ & 6.79 & ans & 079 & 160 & $0.44^{*}$ & 078 & 0002 & 0,2 & 074 \\
\hline Ireland & 0.48 & 0.43 & 070 & 0.47 & bot & 100 & $0.38^{* *}$ & 0.45 & 0.36 & 0.45 \\
\hline fialy & 652 & 0.31 & 039 & 0.67 & $06 x$ & 058 & 200 & 072 & 0.53 & orkyt \\
\hline Netherlands & 060 & 0.7 & 071 & 678 & $0 \times 6$ & 050 & 1608 & 160 & $0.32^{* * *}$ & 067 \\
\hline Portugal & 066 & 0.63 & 0.41 & 963 & 0.67 & 0.36 & 00 & 060 & $1000 \%$ & $1060 \%$ \\
\hline Spain & 620 & 066 & 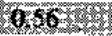 & lon? & 0,2 & 0.47 & 066 & 0.72 .2 & 070 & 160 \\
\hline
\end{tabular}


Table 6: Sector Correlations Before and After the Launch of the Euro (lower left and upper right triangle, respectively)

Correlations of over 0.5 are shaded. $*, * *$, and $* * *(+,++$, and +++$)$ mark significant reductions (increases) at the 10 percent-, 5 percent- and 1 percent-level of significance, respectively

\begin{tabular}{|c|c|c|c|c|c|c|c|c|c|c|c|c|c|c|c|c|c|c|}
\hline & to & anks & & & & Cyct. G. & & & & & & & & & & Techn. & & nUtility \\
\hline to & & 0.614 & 0517 & 060 & $0.54 \%$ & 0.6078 & $0.32^{*+}$ & 05840 & $0.47^{\star \star \star \star}$ & $0.35^{*}$ & $0.40^{ \pm * \star}$ & 0500 & $.05^{\star \star \star *}$ & 0.514 & $0.46^{*}$ & $0.20^{\star \star *}$ & $0.27^{* * * *}$ & $0.43^{\star *}$ \\
\hline & & 760 & $0.27^{* \star}$ & & & $0050 \times 5$ & 0.3 & $0.65=$ & & 0.42 & 0,62 & 078 & $0.29^{* *}$ & 069 & $654=$ & $33^{\star \star *}$ & $0.46^{\star \star * *}$ & $0.67+2$ \\
\hline & & 073 & 1000 & 068 & & & & & & & $23^{\star \star \star}$ & & $-0.13^{* * *}$ & $0.26^{* \pi *}$ & $0.17^{\star \star \star}$ & & $-0.02^{* * *}$ & \\
\hline & & & & & & & & & & & & & & & & & & $t^{* * *}$ \\
\hline & & OT2 & 0 & 0. & & & & & & & $w$ & & & & & & 54 & \\
\hline serv. & 0.82 & 078 & 07 & & & & & & & & & & & 06 & $0.6 \sigma^{*}$ & $0.42^{\star \star \star}$ & $0.45^{\star \star \star *}$ & $0.49^{*}$ \\
\hline & 6,2 & 0.55 & 056 & 65 & $0 \%$ & 061 & & & & & & & & & & & & \\
\hline & o.81 & 0.65 & 0,75 & 05 & ot & & & & & & & 0774 & & 06 & 0 & & $0.31^{* * *}$ & $52 \%$ \\
\hline & 0.65 & 667 & 065 & 06 & & & & & & & & & & $0.44^{n * *}$ & $0.33^{* k *}$ & ;thk & $1^{* \star *}$ & $21^{* * *}$ \\
\hline & 0.4 & 0.41 & 0,4 & 061 & $0 \%$ & & & & & & & & & & $7^{* *}$ & & $0.17^{\star \star \star}$ & $6^{* *}$ \\
\hline & 6 & 082 & 073 & 0,69 & 065 & 072 & 0.45 & & & & & & & & & $0.28^{\pi i k}$ & $0.46^{* \pi *}$ & 062 \\
\hline & & 0.48 & 0.53 & 0.45 & 0.58 & 053 & & & & & & & & & $0.19^{\star \star \star \star}$ & & +1 & \\
\hline & & 0.62 & 0.67 & 062 & 0.09 & 0.68 & & & & & & & & tox & & & & 4. \\
\hline & & & & 0,69 & & & & & & & & & & & & & $32^{+* * *}$ & $7^{* *+}$ \\
\hline & & & & 061 & & & & & & & & & & & & & 72 & \\
\hline & & & 0.60 & 0.6 & & & & & & & & & & & & & & \\
\hline & & & 0.58 & 055 & 070 & 0.61 & 055 & & 0.50 & & 0.58 & 0543 & 0.61 & 0.68 & 064 & .43 & 0.69 & \\
\hline
\end{tabular}


Table 7: Loadings of Rotated Country Factors Before the Launch of the Euro (04:97 - 12:98)

Higher loading factor is shaded; eigenvalues of un-rotated factors are 6.69 and 0.90

\begin{tabular}{|c|c|c|}
\hline & Loadings Factor 1 & Loadings Factor 2 \\
\hline Portugal & 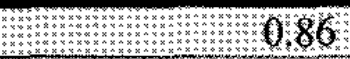 & 0.11 \\
\hline Spain & 0.82 & 0.34 \\
\hline Belgium & W & 0.34 \\
\hline France & W & 0.42 \\
\hline Austria & WW & 0.31 \\
\hline Germany & 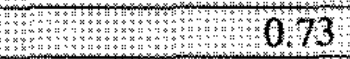 & 0.55 \\
\hline Netherlands & 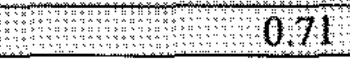 & 0.54 \\
\hline Ireland & 0.18 & 0.88 \\
\hline Finland & 0.36 & 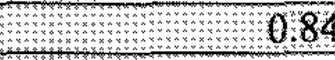 \\
\hline Italy & 0.54 & 0.57 \\
\hline $\begin{array}{l}\text { Percentage of total } \\
\text { variance explained }\end{array}$ & $46.8 \%$ & $29.1 \%$ \\
\hline
\end{tabular}


Table 8: Loadings of Rotated Country Factors After the Launch of the Euro (01:99 - 10:00)

Higher loading factor is shaded; eigenvalues of un-rotated factors are 5.60 and 1.42

\begin{tabular}{|c|c|c|}
\hline & Loadings Factor 1 & Loadings Factor 2 \\
\hline Italy & W & 0.30 \\
\hline France & 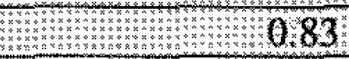 & 0.36 \\
\hline Germany & 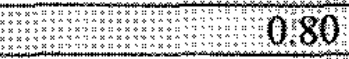 & 0.44 \\
\hline Finland & 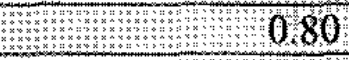 & -0.17 \\
\hline Spain & 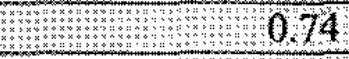 & 0.46 \\
\hline Portugal & $\begin{array}{l}\text { W } \\
\text { W } \\
\text { W }\end{array}$ & 0.15 \\
\hline Netherlands & 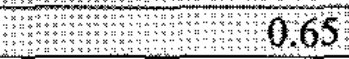 & 0.57 \\
\hline Austria & 0.03 & 0.87 \\
\hline Belgium & 0.18 & 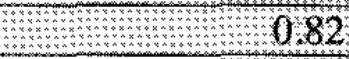 \\
\hline Ireland & 0.33 & 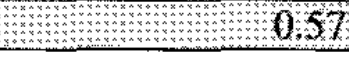 \\
\hline $\begin{array}{l}\text { Percentage of } \\
\text { total variance explained }\end{array}$ & $42.7 \%$ & $27.6 \%$ \\
\hline
\end{tabular}


Table 9: Loadings of Rotated Sector Factors Before the Launch of the Euro (04:97 - 12:98)

Highest loading factor is shaded; eigenvalues of un-rotated factors are $11.93,1.17$, and 0.71

\begin{tabular}{|c|c|c|c|}
\hline & Loadings Factor 1 & Loadings Factor 2 & Loadings Factor 3 \\
\hline Technology & 0.83 & 0.28 & 0.18 \\
\hline Insurance & 0.82 & 0.08 & 0.37 \\
\hline Auto & 0.79 & 0.34 & 0.33 \\
\hline Bank & 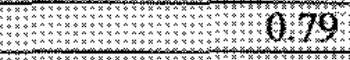 & 0.20 & 0.36 \\
\hline Financial services & 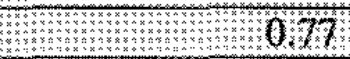 & 0.12 & 0.52 \\
\hline Basic resources & 0.75 & 0.38 & 0.30 \\
\hline Cycl. goods \& services & 0774 & 0.36 & 0.34 \\
\hline Inds. goods \& services & 073 & 0.42 & 0.34 \\
\hline Construction & Why & 0.48 & 0.36 \\
\hline Telecom & 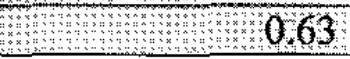 & 0.19 & 0.61 \\
\hline Healthcare & 0.14 & 0.82 & 0.31 \\
\hline Energy & 0.28 & 0.65 & 0.35 \\
\hline Chemical & 0.54 & 0.63 & 0.25 \\
\hline Utility Suppliers & 0.28 & 0.37 & 074 \\
\hline Retail & 0.35 & 0.25 & 0.7 \\
\hline Media & 0.27 & 0.35 & 0,67 \\
\hline Non-cycl. Goods & 0.47 & 0.38 & 0.64 \\
\hline Food \& beverages & 0.48 & 0.34 & 0.57 \\
\hline $\begin{array}{l}\text { Percentage of } \\
\text { total variance explained }\end{array}$ & $37.6 \%$ & $16.9 \%$ & $22.3 \%$ \\
\hline
\end{tabular}


Table 10: Loadings of Rotated Country Factors After the Launch of the Euro (01:99 - 10:00)

Highest loading factor shaded; eigenvalues of un-rotated factors are 7.86, 2.92, and 1.60

\begin{tabular}{|c|c|c|c|}
\hline & Loadings Factor 1 & Loadings Factor 2 & Loadings Factor 3 \\
\hline Financial services & $0.8 \%$ & 0.17 & 0.26 \\
\hline Non-cycl. goods & $0 \% 9$ & 0.32 & 0.15 \\
\hline Bank & 6067 & 0.34 & 0.31 \\
\hline Food \& beverages & 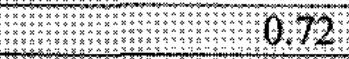 & -0.37 & 0.19 \\
\hline Insurance & 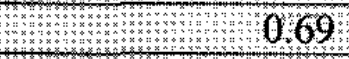 & 0.34 & 0.22 \\
\hline Retail & 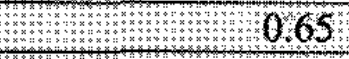 & 0.23 & 0.18 \\
\hline Healthcare & $w_{W}$ & -0.01 & -0.02 \\
\hline Utility Suppliers & $=0.61$ & 0.61 & -0.01 \\
\hline Media & 0.04 & 090 & -0.09 \\
\hline Telecom & 0.24 & 0.88 & $0 . \overline{01}$ \\
\hline Technology & 0.10 & 0.86 & 0.08 \\
\hline Inds. goods \& services & 0.33 & 075 & 0.28 \\
\hline Basic resources & 0.13 & -0.10 & 0.84 \\
\hline Chemical & $0 . \overline{40}$ & -0.01 & 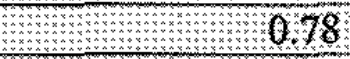 \\
\hline Energy & -0.04 & 0.08 & 0.7 \\
\hline Auto & 0.56 & 0.11 & 0.60 \\
\hline Construction & 0.38 & 0.48 & 0.52 \\
\hline Cycl. goods \& services & 0.48 & 0.40 & 0.50 \\
\hline $\begin{array}{l}\text { Percentage of } \\
\text { total variance explained }\end{array}$ & $28.3 \%$ & $23.4 \%$ & $17.1 \%$ \\
\hline
\end{tabular}


Figure 1: Relative Market Capitalization of Stock Markets in the EMU; Average Values 01:99 - 10:00

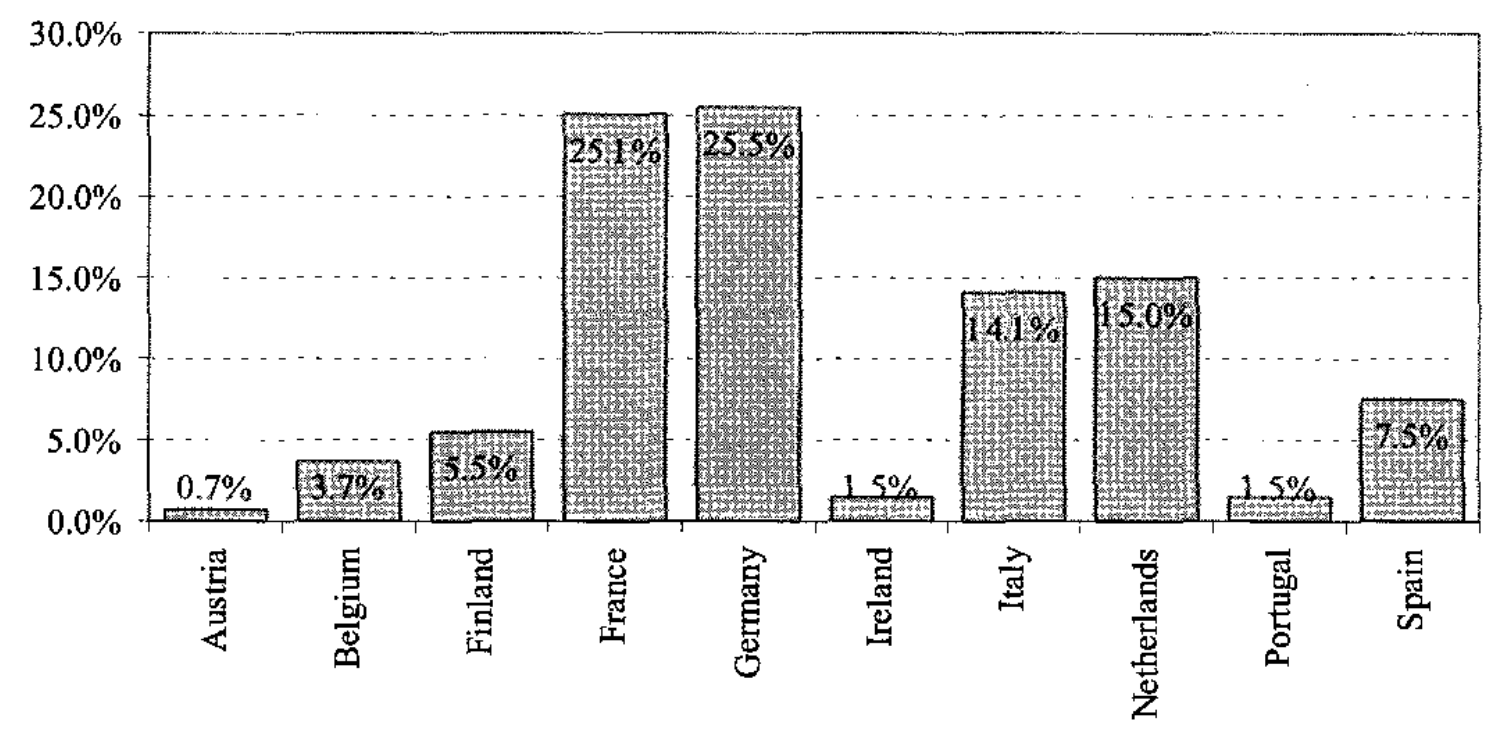


Figure 2: Relative Market Capitalization of Industry Sectors in the EMU; Average Values 01:99 - 10:00

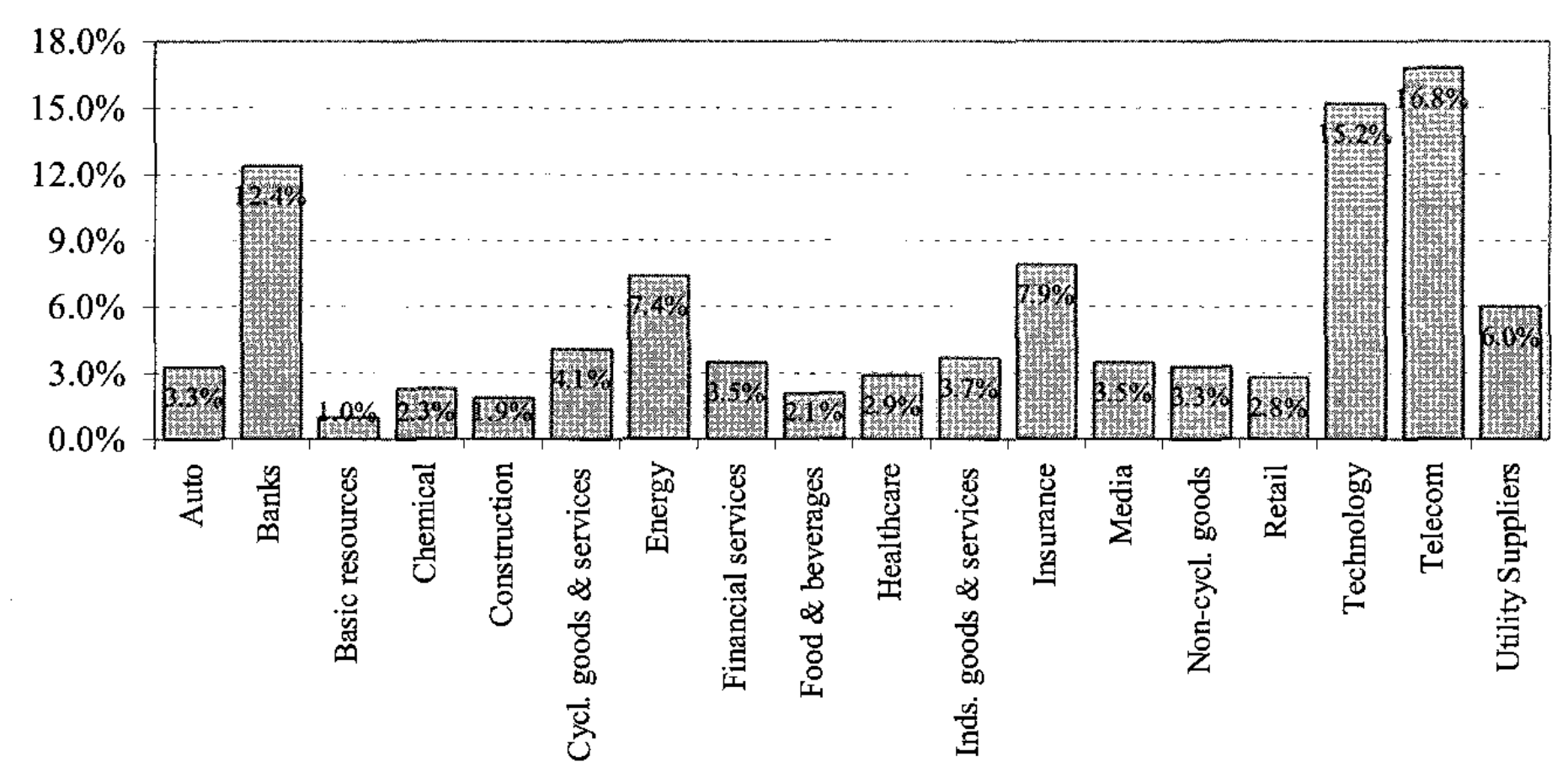


Figure 3: Variance Decomposition of the Entire Sample Before and After the Introduction of the Euro

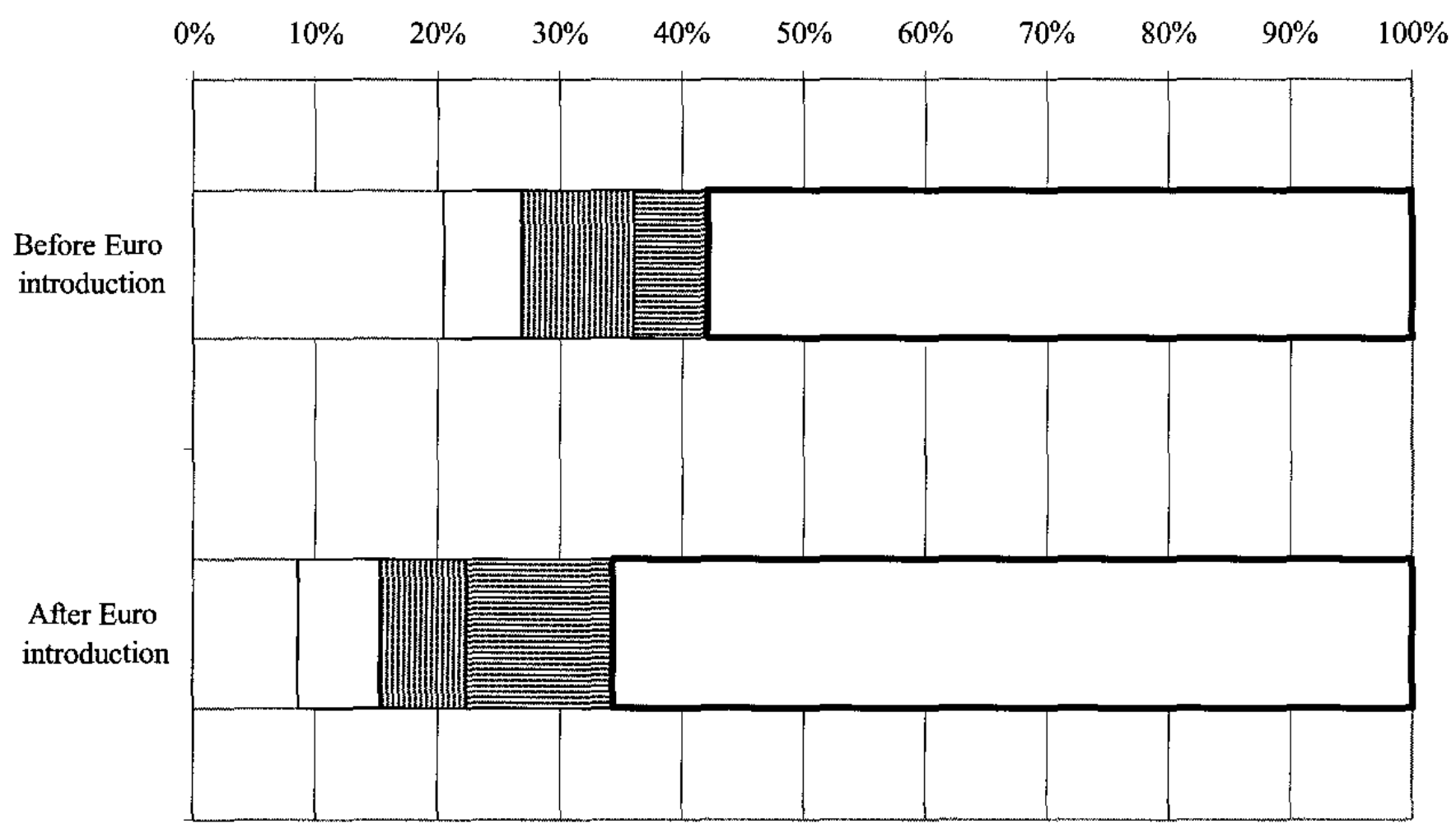

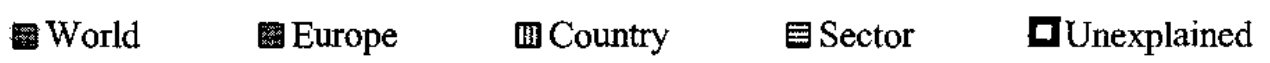


Figure 4: Variance Decomposition of Stocks According to Country Grouping After the Introduction of the Euro

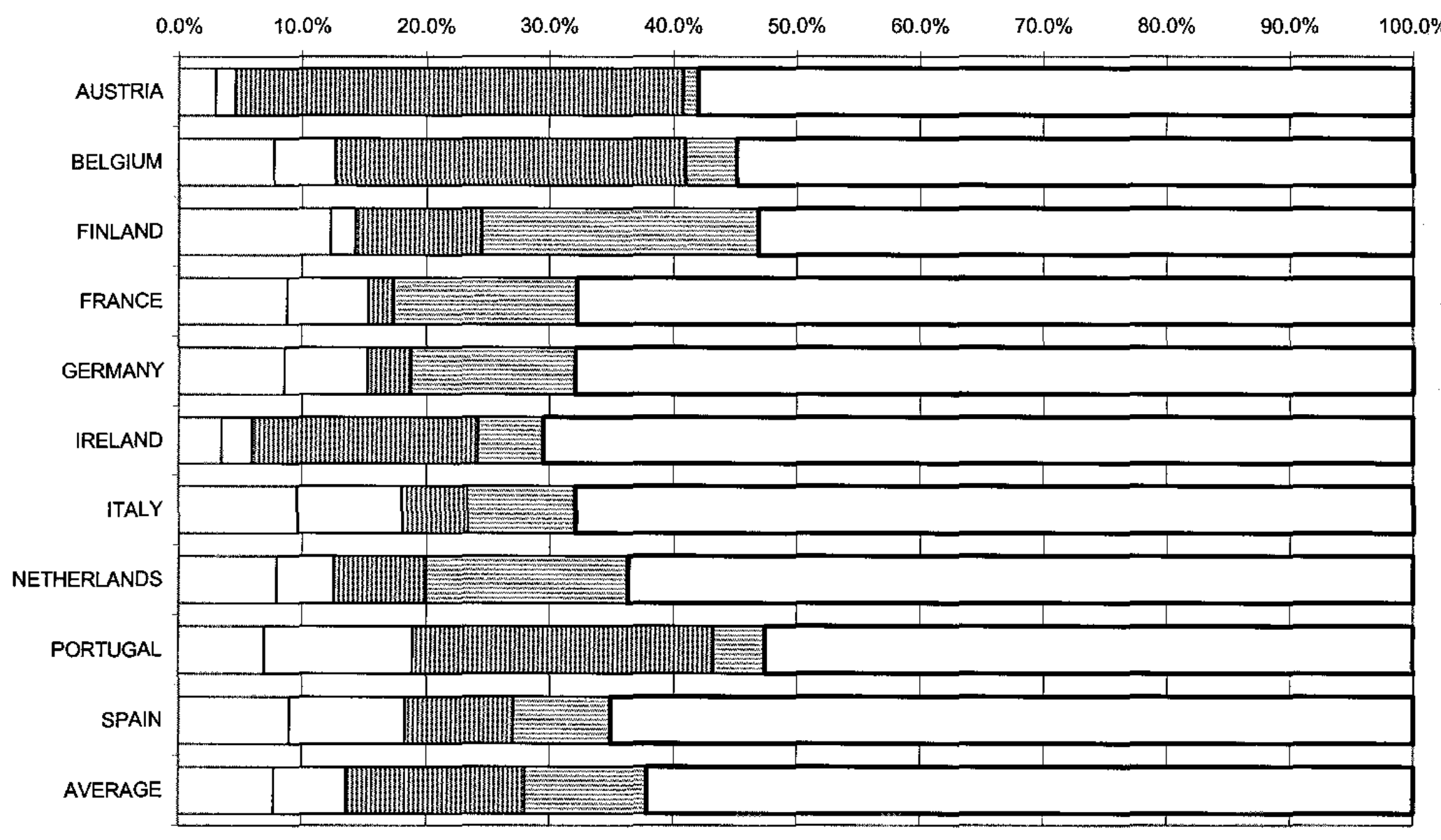

World Europe Gountry Gector aUnexplained 
Figure 5: Differences in Variance Components of Single Stocks Before and After the Introduction of the Euro Grouped by Countries

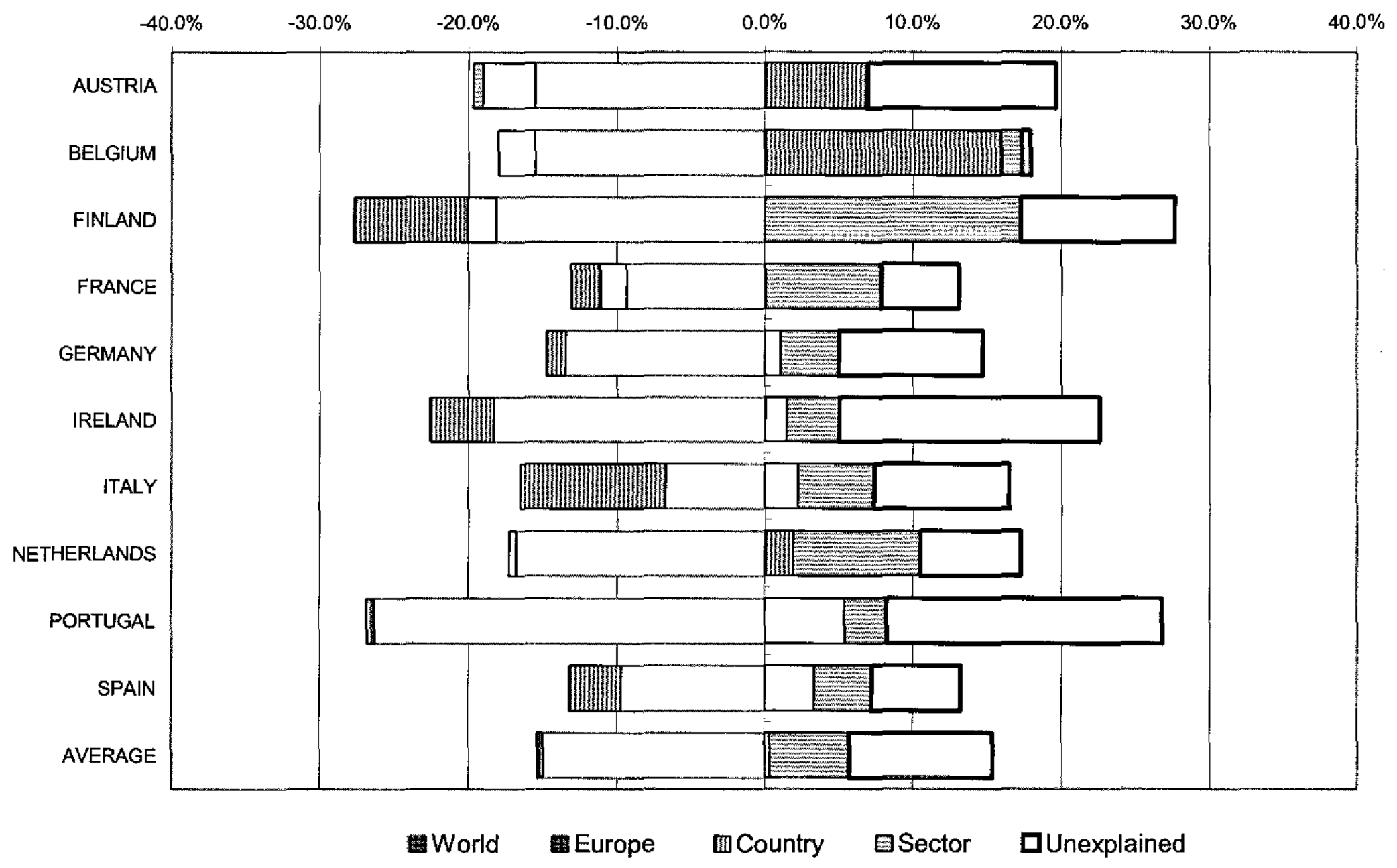


Figure 6: Variance Decomposition of Stocks According to Country Grouping After the Introduction of the Euro

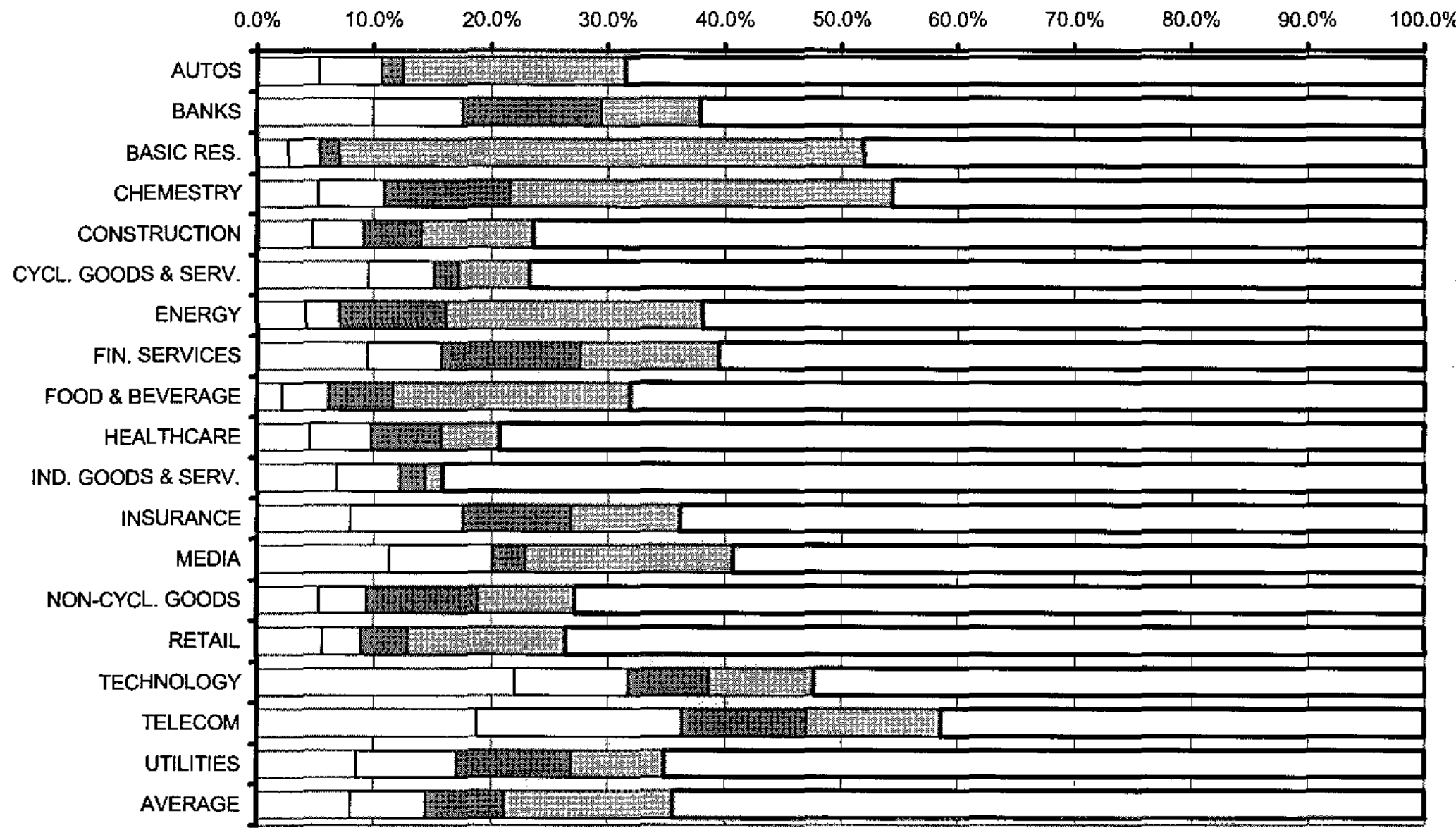

World Europe $\quad \square$ Country $\quad$ Sector $\square$ Unexplained


Figure 7: Differences in Variance Components of Single Stocks Before and After the Introduction of the Euro Grouped by Sectors

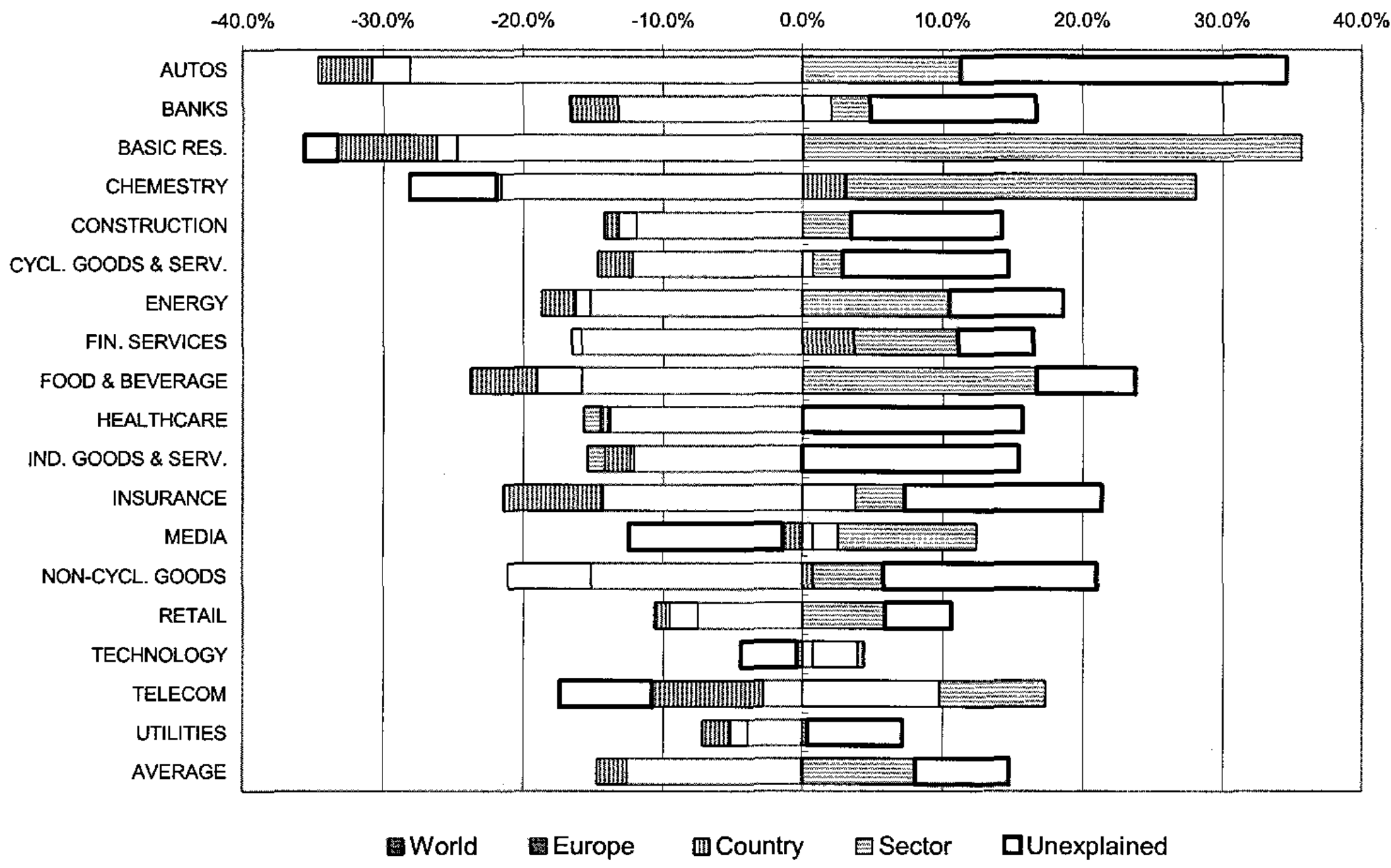


Figure 8: Dendogram of Country Indices Before (left) and After the Launch of the Euro (right)

Complete linkage based on coefficients of correlation
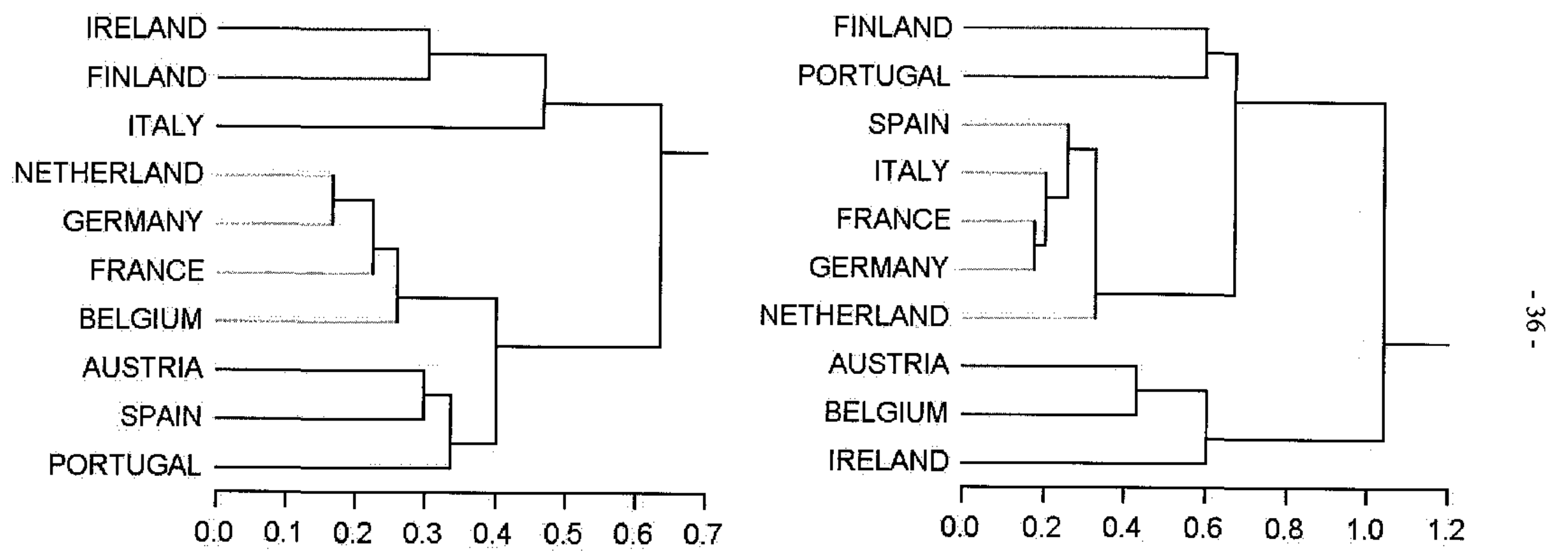
Figure 9: Dendogram of Sector Indices Before (left) and After the Launch of the Euro (right)

Complete Linkage Based on Coefficients of Correlations
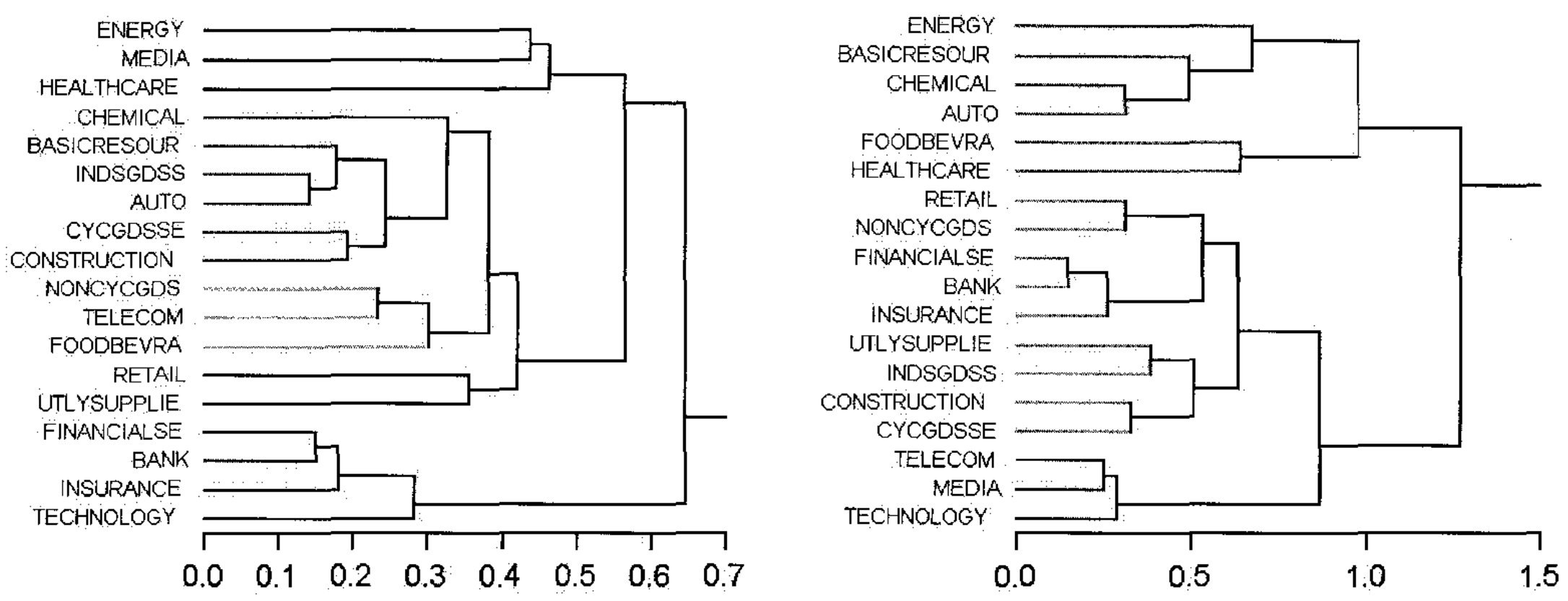


\section{REFERENCES}

Baca, Sean P., Brian L. Garbe, and Richard A. Weiss, 2000, "The Rise of Sector Effects in Major Equity Markets," Financial Analysts Journal, September/October, pp. 34-40.

Beckers, Stan, 1999, "Investment Implications of a Single European Capital Market," The Journal of Portfolio Management, Spring, pp. 9-17.

Beckers, Stan; Gregory Connor, and Ross Curds, 1996, "National versus Global Influences on Equity Returns," Financial Analysts Journal, March/April, pp. 31-39.

Beckers, Stan, Richard Grinold, Andrew Rudd, and Dan Stefek, 1992, "The Relative Importance of Common Factors across the European Equity Markets," Journal of Banking and Finance, Vol.16, pp. 75-95.

Bertero, E., and C. Mayer, 1990, "Structure and Performance: Global Interdependence of Stock Markets Around the Crash of October 1987," European Economic Review, Vol. 34, pp. 1155-180.

Biais, Bruno, 1999, "European Stock Markets and European Unification," in Jean Dermine and Pierre Hillion, European Capital Markets with a Single Currency (Oxford University Press), pp. 236-62.

Bank for International Settlements (BIS), 2000, Annual Report, Basel.

Cavaglia, Stefano; Christopher Brightman, and Michael Aked, 2000, "The Increasing Importance of Industry Factors," Financial Analysts Journal, September/October, pp. 41--55.

De Santis, Giogio, Bruno Gerard, and Pierre Hillion, 1999, "The Single European Currency and World Equity Markets," in Jean Dermine and Pierre Hillion, European Capital Markets with a Single Curerrency (Oxford University Press), pp. 205-35.

Drummen, Martin, and Heinz Zimmermann, 1992, "The Structure of European Stock Returns," Financial Analysts Journal, July/August, pp. 15-26.

Freiman, Eckhard, 1998, "Economic Integration and Count Allocation in Europe," Financial Analysts Journal, September/October, pp. 32-41.

Goldman Sachs Investment Research, 1998, "Sectors versus Country: When Is an Asset Class an Asset Class?” Portfolio Strategy, March, p. 21.

Heston, Steven L., and K. Geert Rouwenhorst, 1994, "Does Industrial Structure Explain the Benefits of International Diversification?” Journal of Financial Economics, Vol. 36, pp. $3-27$. 
Heston, Steven L., K. Geert Rouwenhorst, and Roberto E. Wessels, 1995, "The Structure of International Stock Returns and the Integration of Capital Markets," Journal of Empirical Finance, Vol. 2, pp. 173-97.

Jennrich, Robert I., 1970, “An Asymptotic Chi-Square Test for the Equality of Two Correlation Matrices," Journal of the American Statistical Association, Vol. 65, No. 330, pp. 904-12.

Kaplanis, Evi C., 1988, "Stability and Forecasting of the Comovement Measures of International Stock Market Returns," Journal of International Money and Finance, Vol. 8, pp. 63-75.

King, M., and S. Wadhwani, 1990, "Transmission of Volatility between Stock Markets," Review of Financial Studies, Vol. 3, pp. 5-33.

Longin, Francois, and Bruno Solnik, 1995, "Is the Correlation in International Equity Returns Constant: 1960-1990?" Journal of International Money and Finance, Vol. 14, pp. 3-26.

Morgan Stanley Dean Witter, 1998, Global Equity and Derivative Markets, Vol. 8, No. 6 (June).

Naughton, Tony, 1996, "A Factor Analysis of Equity Market Relationships in Asia," Applied Economics Letters, Vol. 3, pp. 725-28.

Prati, Alessandro, and Garry J. Schinasi, 1997, "European Monetary Union and International Capital Markets: Structural Implications and Risks," IMF Working Paper 97/62 (Washington: International Monetary Fund).

Ratner, M., 1992, "Portfolio Diversification and the Inter-temporal Stability of International Indices," Global Finance Journal, Vol. 3, pp. 67-78.

Roll, Richard, 1992, "Industrial Structure and the Comparative Behavior of International Stock Market Indices," The Journal of Finance, Vol. XLVII, No. 1, pp. 3-41.

Rouwenhorst, K. Geert, 1999, "European Equity Markets and the EMU," Financial Analyst Journal, May/June, pp. 57-64. 